\title{
PREVALÊNCIA E RISCO DE QUEDAS EM IDOSOS
}

\section{ARTIGO DE REVISÃO}

JÚNIOR, Francisco Geová Goveia Silva ${ }^{1}$

JÚNIOR, Francisco Geová Goveia Silva. Prevalência e risco de quedas em idosos. Revista Científica Multidisciplinar Núcleo do Conhecimento. Ano 04, Ed. 10, Vol. 10, pp. 139-145. Outubro de 2019. ISSN: 2448-0959, Link de acesso: https://www.nucleodoconhecimento.com.br/saude/prevalencia-e-risco

\section{RESUMO}

Introdução: O grande número de ocorrências como quedas de idosos é calculada em relação ao número de casos evidenciados quanto a incidência e prevalência registradas de quedas no Brasil. De caráter multifatorial, a sua ocorrência tem-se tornado uma das grandes síndromes geriátricas na Saúde Pública. Objetivo: Esta pesquisa teve como objetivo realizar uma revisão de literatura buscando aprofundar os conhecimentos sobre a prevalência e risco de quedas em idosos. Metodologia: $O$ estudo trata-se de uma pesquisa de revisão da literatura. Para a elaboração dessa pesquisa foram realizadas buscas nas bases de dados SciELO, Google Acadêmico, BVS e Pubmed, cujos descritores selecionados foram: envelhecimento, acidentes por quedas, idoso. Após a análise, foram selecionados 36 artigos, onde realizadas as devidas ponderações e considerações dos temas obtidos, selecionou-se 15 artigos do total para compor esta pesquisa. Resultado: Guimarães (2005) relata que a diminuição da flexibilidade está associada à ocorrência de quedas, provocando principalmente a diminuição de mobilidade no quadril, joelhos, tornozelos e da coluna vertebral, proporcionando o surgimento de alterações na marcha como também dificuldades no desempenho de funções. Conclusão: Durante toda a pesquisa, percebeu-se que as quedas apresentam fatores de risco que com atenções de educação e prevenção podem ser reduzidas e até mesmo evitadas. Novos estudos são essenciais para que

\footnotetext{
${ }^{1}$ Bacharel em Fisioterapia.
} 
se entenda a evolução do envelhecimento e assim possam ser traçadas estratégias de educação, promoção e prevenção para idosos vitimados.

Palavras-chave: envelhecimento, acidentes por quedas, idoso.

\section{INTRODUÇÃO}

O grande número de ocorrências como quedas em idosos é calculada em relação ao número de casos que são evidência quanto a incidência e prevalência em que são registrados no Brasil. De caráter multifatorial, a sua ocorrência tem-se tornado uma das grandes síndromes geriátricas na Saúde Pública. (LEMOS et al, 2017).

Cair é um risco que qualquer pessoa corre, porém com o decorrer do tempo e avanço da idade, as quedas podem se tornar mais comuns, podendo resultar em consequências de grande impacto aqueles que necessitam de maiores cuidados. Pessoas com idade avançada possuem características que carecem de atenção primordial, e um mínimo de descuido pode ocasionar graves acidentes em situações as quais não teriam o risco de sofrer uma queda. (PAULA, 2015).

Com o avanço da idade a mortalidade e a morbidade têm aumentado gradualmente em meio a vários fatores, tais como restrição a mobilidade, depressão, perda da autonomia, perda da capacidade funcional, fraturas e a diminuição da qualidade de vida para esses indivíduos. Também se enquadram as condições psicológicas e socioeconômicas que podem causar uma sobrecarga no sistema básico de saúde, podendo resultar em muitos casos na perda da qualidade de vida dos idosos, afetando não só os familiares, mas tudo que está a sua volta deve sofrer uma adaptação, onde a rotina deverá ser voltada visando à recuperação funcional ou a adaptação do idoso logo após seu trauma. (GASPAROTTO, 2012; COIMBRA, 2012).

A população mundial vem envelhecendo em maior intensidade e de forma crescente, é relevante que sejam realizados estudos que venham a identificar a prevalência e o risco de quedas em idosos, adotando meios de prevenção de riscos e agravos 
promovendo uma melhor qualidade de vida e independência funcional. Esta pesquisa teve como objetivo realizar uma revisão de literatura buscando aprofundar os conhecimentos sobre a prevalência e risco de quedas em idosos.

\section{METODOLOGIA}

O estudo trata-se de uma pesquisa de revisão da literatura. Para a elaboração dessa pesquisa foram realizadas buscas nas bases de dados Scielo, Google Acadêmico, BVS e Pubmed, cujos descritores selecionados foram: envelhecimento, acidentes por quedas, idoso. Após a análise, foram selecionados 36 artigos, onde realizadas as devidas ponderações e considerações dos temas obtidos, selecionou-se 15 artigos do total para compor esta pesquisa.

Os critérios de inclusão foram: ser artigo científico; ter sido publicado em língua portuguesa, inglesa ou espanhola; estar disponível na íntegra; contemplar o tema da pesquisa. Os critérios de exclusão adotados foram: publicações que fugissem do tema proposto, resumos de congresso, vídeos.

\section{RESULTADOS}

Segundo Adams (1999), em seu estudo ele mostra que os grupos mostraram ocorrência de quedas em um período de 12 meses, apresentando também que idosos negros apresentaram uma maior taxa em relação a outras etnias declaradas, como também para variáveis quase quedas e o medo de cair. Essa variável é importante pelo fato de alguns estudos mostrarem que o envelhecimento provoca uma redução da amplitude de movimentos.

Guimarães (2005) relata que a diminuição da flexibilidade está associada à ocorrência de quedas, provocando principalmente a diminuição de mobilidade no quadril, joelhos, tornozelos e da coluna vertebral, proporcionando o surgimento de alterações na marcha como também dificuldades no desempenho de funções.

Percebe-se que é enorme o número de quedas sofridas por idosos, provando em mudanças em todo o seu contexto do seu dia a dia, tanto pela queda, como pelo medo 
de voltar a cair. As quedas têm provocado imensos impactos dentre eles restrição as atividades do dia a dia, o idoso acaba se isolando, diminuição da autoestima, depressão, declínio da saúde, e além de tudo isso passa a correr o risco de institucionalização. (CARTER, 2001; STALENHOEF 2000).

Segundo Owings et al (1999), a partir do momento em idosos caem e são hospitalizados, é bastante comum que o mesmo fique imobilizado ou até mesmo inválido, isso porquê após a queda, a tendência é causar a limitação para AVDs, repercutindo negativamente na qualidade de vida, sendo necessário cada vez mais de um suporte familiar e cuidadores.

Segundo Berg et al (1997), as quedas em idosos ocorrem durante a realização de atividades simples como caminhar e realizar limpeza, o maior número de ocorrências se dá pela realização de atividades com maior risco, como subir e descer escadas, subir em cadeira para tentar alcançar objetos altos e outros por subir em andaimes. Problemas ambientais também representaram causas frequentes, em que tropeços e escorregões foram grande causa de quedas.

Estimativas mundiais apontam que cerca de $30 \%$ dos idosos caem pelo menos uma vez ao ano, e 13\% de forma recorrente (ORGANIZAÇÃO MUNDIAL DA SAÚDE, 2010).

As quedas podem ser classificadas de acordo com a sua frequência, o tempo que o idoso permanece no chão, e se houve presença ou não de lesões. A queda acidental é aquele evento que muito dificilmente irá se repetir, e decorre de uma causa extrínseca, podendo ser pela presença de um fator de risco ambiental, como por exemplo, um piso escorregadio, ambiente com baixa iluminação, órteses mal projetadas entre várias outras atitudes que colocam em risco o bem estar físico do indivíduo. (JÚNIOR; HECKMAN, 2011; PERRACINI, 2011).

Nascimento (2014) confirmou em seu estudo realizado na zona urbana de Uberaba $M G$, que as quedas ocorreram principalmente no pátio/quintal com margem de $22,8 \%$, nas ruas e avenidas com $16,5 \%$, calçadas $14,6 \%$ e da própria altura $83,0 \%$, onde 
25,7\% precisaram ser hospitalizados onde tiveram lesões como escoriações e fraturas. Alguns fatores extrínsecos como tontura/vertigem e alteração de equilíbrio, e a presença de pisos escorregadios, molhados, degraus altos e desnivelados puderam ser percebidos como causadores de quedas. Os idosos apresentaram repercussões na sua vida cotidiana como dificuldade para andar, medo de cair novamente, necessário de ajuda para realizar as AVDs e também isolamento social.

Os idosos com faixa etária entre 60 e 79 anos de idade com o uso de dispositivo auxiliar de marcha são os maiores preditores do risco de quedas, justamente devido ao déficit de equilíbrio que é ocasionado por todo processo de envelhecimento e pela dependência enquanto executa a marcha. Durante a pesquisa percebeu-se que a atividade física está presente na rotina de maior parte dos idosos, atuando como fator preventivo para quedas, trabalhando o fortalecimento muscular desses indivíduos. (OLIVEIRA, 2017; DA SILVA BALICA, 2017)

Santer; Bruggemann; Silva (2012) relata que após entrevistarem os indivíduos perceberam que as quedas são mais frequentes na população idosa e principalmente do sexo feminino. Tendo como principais riscos não ter renda, ter renda de dois salários mínimos, não estar aposentada e ter 80 anos ou mais. Já dentre os homens mostram quedas entre 80 anos ou mais e ter uma renda de até três salários mínimos.

A persistência de quedas em idosos mostrou-se em níveis elevados, bem como também demonstrado por vários estudos nacionais, que se trata da queda ao idoso no âmbito de saúde publica. Entre os fatores que são relacionados à queda, foram identificados alguns como o analfabetismo, as dores crônicas e os casos de isquemia cerebral. Toda a investigação realizada mostra que esses fatores favoráveis a quedas, podem ser modificados e evitados, bastando somente realizar ações voltadas a educação, saúde e prevenção podendo reduzir positivamente as chances de quedas, como também os danos causados ao indivíduo. (LIMA et al, 2017). 


\section{CONCLUSÃO}

Durante toda a pesquisa, percebeu-se que as quedas apresentam fatores de risco que com atenções de educação e prevenção podem ser reduzidas e até mesmo evitadas. Alguns fatores de risco citados em estudos foram idade avançada, sexo feminino, fragilidade e alterações de equilíbrio, trazendo consequências devastadoras a esses indivíduos, sendo elas medo de cair, prejuízo emocional, fraturas e escoriações que podem causar uma limitação ou até invalidez ao indivíduo, tornando-o incapaz de realizar AVDs sozinho, ou em casos mais graves levando ao óbito.

A população idosa tem crescido alarmantemente, portanto, faz-se necessário à realização de estudos sobre os problemas que mais afetam essa população. Novos estudos são essenciais para que se entenda a evolução do envelhecimento e assim possam ser traçadas estratégias de educação, promoção e prevenção para idosos vitimados.

\section{REFERÊNCIAS}

ADAMS, Kent; O'SHEA, Patrick; O'SHEA, Katie L. Aging: its effects on strength, power, flexibility, and bone density. Strength and conditioning Journal, v. 21, p. 6577, 1999.

BERG, William P. et al. Circumstances and consequences of falls in independent community-dwelling older adults. Age and ageing, v. 26, n. 4, p. 261-268, 1997.

CARTER, Nick D.; KANNUS, Pekka; KHAN, Karim. Exercise in the prevention of falls in older people. Sports medicine, v. 31, n. 6, p. 427-438, 2001.

FALSARELLA, Gláucia Regina; GASPAROTTO, Lívia Pimenta Renó; COIMBRA, Arlete Maria Valente. Quedas: conceitos, frequências e aplicações à assistência ao idoso. Revisão da literatura. Revista Brasileira de Geriatria e Gerontologia, v. 17, n. 4, p. 897-910, 2014. 
GUIMARÃES, Joanna Miguez Nery; FARINATTI, Paulo de Tarso Veras. Análise descritiva de variáveis teoricamente associadas ao risco de quedas em mulheres idosas. Rev Bras Med Esporte, v. 11, n. 5, p. 299-305, 2005.

LEMOS, Gabriela Fernandes et al. Fatores Associados a Quedas em Idosos de uma Unidade Básica de Saúde. ID ON LINE REVISTA MULTIDISCIPLINAR E DE PSICOLOGIA, v. 11, n. 38, p. 150-165, 2017.

LIMA, Alisson Padilha de et al. Prevalência e fatores associados às quedas em idosos de Estação-RS: estudo transversal de base populacional. Cadernos Saúde Coletiva, v. 25, n. 4 , p. $436-442,2017$.

NASCIMENTO, Janaína Santos et al. Prevalência de quedas e fatores associados em idosos da zona urbana do município de Uberaba-Minas Gerais. 2014.

OWINGS, Tammy M. et al. Exercise: Is it a solution to falls by older adults?. Journal of Applied biomechanics, v. 15, n. 1, p. 56-63, 1999.

ORGANIZAÇÃO MUNDIAL DE SAÚDE. Relatório global da OMS sobre prevenção de quedas na velhice. Edição de Marília Prado Louvison e Tereza Etsuko da Costa Rosa. Secretaria da Saúde. Vigilância e prevenção de quedas em idosos. São Paulo (Estado), 2010.

Disponível

em: $<$ http://bvsms.saude.gov.br/bvs/publicacoes/relatorio_prevencao_quedas_velhice.pdf >. Acesso em: 02 novembro de 2018.

OLIVEIRA, Francisco Braz Milanez; DA SILVA BALICA, Bruna Caroline. Prevalência de quedas e fatores associados em idosos. Revista Eletrônica Acervo Saúde/Electronic Journal Collection Health ISSN, v. 2178, p. 2091.

PAULA, Ludmila Schettino Ribeiro de. Modelo preditivo do risco de quedas para idosos residentes em comunidade. Dissertação (Programa de Pós-Graduação em Enfermagem e Saúde), Universidade Estadual do Sudoeste da Bahia, Jequié, 2015. 
PAIXÃO, J. R.; HECKMANN, M. Distúrbios da postura, marcha e quedas. Freitas EV, Py L, organizadores. Tratado de Geriatria e Gerontologia. Rio de Janeiro: Guanabara Koogan, p. 624-34, 2002.

STALENHOEF, Paul A. et al. The construction of a patient record-based risk model for recurrent falls among elderly people living in the community. Family Practice, v. 17, n. 6, p. 490-496, 2000.

SANTER, T. ; BRUGGEMANN, C. F. V. P. ; SILVA, O. M. P. . PREVALÊNCIA DE QUEDAS ENTRE IDOSOS FREQUENTADORES DAS UNIDADES BÁSICAS DE SAÚDE DO MUNICÍPIO DE PALMITOS, SANTA CATARINA, E FATORES ASSOCIADOS. Revista de Saúde Pública de Santa Catarina , v. 5, p. 32-43, 2012.

Enviado: Abril, 2019.

Aprovado: Outubro, 2019. 